\title{
UNIDADES FRASEOLÓGICAS CON ESTRUCTURA COMPARATIVA: DIVERGENCIAS EN SU DELIMITACIÓN Y CLASIFICACIÓN LEXICOGRÁFICA
}

\author{
Phraseological units with comparative structure: divergences in their \\ delimitation and lexicographic classification
}

\author{
Sergio Cordero Monge ${ }^{1}$
}

\begin{abstract}
RESUMEN
Un problema bastante común en la lexicografía del español es el tratamiento disímil que reciben determinados tipos de unidades fraseológicas. En esta ocasión, nos vamos a referir al tipo de construcciones comparativas que, por presentar las características de fijación e idiomaticidad (aunque sea parcial) propias de las unidades fraseológicas, suelen analizarse como locuciones de diversa categoría gramatical, o bien como unidades no propiamente locucionales.
\end{abstract}

Palabras clave: lexicografía, fraseología, diccionario, locución.

\begin{abstract}
In general, a very common problem in the lexicography of Spanish language is the dissimilar treatment of certain types of phraseological units. On this occasion, we will refer to the type of comparative constructions that, for having as characteristics the features of lexical fixation and idiomatic nature (even if partial), that are distinguishing features of phraseological units, are usually analyzed as fixed complex units of different grammatical categories, or even as non-fixed complex units at all.
\end{abstract}

Key Words: lexicography, phraseology, dictionary, fixed complex unit.

\section{Introducción}

Al compararse variados repertorios lexicográficos, se puede apreciar que determinadas clases de unidades fraseológicas no son analizadas de la misma manera, aunque se trate de la misma unidad léxica. Como se verá, las secuencias con estructura comparativa, del tipo dormir como un lirón y negro como el carbón, suscitan opiniones divergentes en cuanto a su delimitación sintagmática y funcionamiento sintáctico, de manera que, tanto en el nivel del análisis fraseológico como en la práctica lexicográfica, es

${ }^{1}$ Universidad de Costa Rica. Profesor de la Escuela de Filología, Lingüística y Literatura. Costa Rica Correo electrónico: sergiocmcr@gmail.com

Recepción: 4-4-2017 Aceptación: 12-07-2017 
común encontrar distintas soluciones: a) la unidad es locución, verbal o adjetiva según sea el núcleo y la función sintáctica que desempeñe; b) la unidad es una colocación compleja de un verbo o un adjetivo y una locución adverbial; c) la unidad es locución adverbial, adjetiva o policategorial conformada únicamente por la expresión comparativa; d) la unidad es locución elativa.

\section{Construcciones comparativas}

Se distinguen dos tipos de construcciones comparativas. Por una parte, las construcciones comparativas de la sintaxis libre, como la que aparece en el siguiente comentario:

(1) Las mujeres que conozco que toman mucho no toman como un mae que realmente toma guaro, además se les nota más rápido cuando están tapis (...) (forodecostarica.com).

Y, por otra parte, las comparativas fraseológicas, ${ }^{2}$ como la que se encuentran en este nuevo ejemplo:

(2) Ayer la bajé [una dieta] y me dispuse a comenzarla, entonces hoy me pesé y ¡sorpresa! Bajé a 79 kilos desde la última vez que me subí a la báscula!!! No entiendo cómo, si en diciembre harté y bebí como un cosaco (...). Voy más motivado entonces, jajaja (...) (forodecostarica.com).

En ambos casos, se entiende que se elide el adverbio comparativo tanto: "toman [tanto] como un mae que realmente toma guaro" y "bebí [tanto] como un cosaco".

A diferencia de las construcciones comparativas de la sintaxis libre, las comparativas fraseológicas tienen una función intensificadora de grado máximo. Y esta función elativa, superlativa o ponderativa prevalece sobre la función comunicativa o

2 Otras denominaciones para las comparativas fraseológicas son: "comparativas prototípicas" (Gutiérrez Ordóñez, 1997, p. 64; Real Academia Española; Asociación de Academias de la Lengua Española, 2010, p. 871; Suñer Gratacós, 2013), “comparativas elativas" (Gutiérrez Ordóñez, 1997, p. 64), "comparativas estereotipadas” (Koike, 2001, p. 59; García-Page, 2008a, p. 318; García-Page, 2008b) y “comparaciones fijas" (Mellado Blanco, 2012), entre otras. 
referencial. Respecto a esta característica diferenciadora entre las comparativas fraseológicas (o comparativas prototípicas) y las comparativas de la sintaxis libre (o comparativas propias), Suñer Gratacós apunta:

Las comparativas prototípicas difieren interpretativamente de las propias en dos aspectos fundamentales. Por un lado, en que se toma como base de la comparación un genérico en vez de una expresión nominal específica y, por otro, en que las codas prototípicas no denotan grado relativo de una dimensión sino un grado extremo asociado a una ponderación subjetiva (2013, p. 338).

La intensificación en grado extremo de las comparativas fraseológicas se sustenta en el rango de prototipo que tiene el término comparante (el segundo término o la coda de la comparación), que se presenta ante la comunidad de hablantes como el máximo referente de la noción comparada. Por ejemplo:

(3) Por primera vez vi sus ojos: eran negros como el carbón; sin pupila, sin iris, solo dos orbes negros que reflejaban la luz roja y blanca de la marquesina (http://videojuegos.cr).

Así, en "sus ojos eran negros como el carbón”, el término comparante carbón simboliza la negrura total, el máximo exponente de la noción comparada, que es "la negrura", de tal manera que la negrura de estos ojos es comparable a la negrura del carbón, en otras palabras, y utilizando el superlativo: "Sus ojos eran negrísimos" (véase GarcíaPage, 2008a, p. 318).

La propiedad intensificadora de las construcciones comparativas fraseológicas aparece lexicográficamente indicada en varios artículos del Diccionario fraseológico documentado del español actual (DFDEA), de Seco, Andrés y Ramos, donde la marca gramatical (Constr de sent comparativo) y la explicación semántica se funden en un enunciado definitorio en metalengua de signo, ${ }^{3}$ por ejemplo:

3 Según se entienden los términos "metalengua de signo" y "metalengua de contenido" en Seco (2003, pp. 3334); y este a partir de Rey-Debove (1971) Étude linguistique et sémiotique des dictionnaires français contemporains. La definición en metalengua de signo (definición impropia) es una explicación del uso o de la función de la palabra definida mientras que la definición en metalengua de contenido (definición propia) presenta el contenido semántico -el significado- de la palabra definida. 
como un lirón. (col) Constr de sent comparativo usada para ponderar lo profundamente que duerme una pers. Gralm con el v dormir. "I (Seco, Andrés y Ramos, 2004, p. 587).

como el carbón (o más que el carbón). Constr de sent comparativo usada para ponderar la negrura. Frec con el adj negro. \| (Seco, Andrés y Ramos, 2004, p. 250).

Sin embargo, y ya que es nuestro interés señalar algunas divergencias en el tratamiento lexicográfico de este tipo de unidades, en este mismo diccionario encontramos definiciones ya no en metalengua de signo, es decir, a modo de explicaciones sobre el uso y la función, sino en metalengua de contenido, aportando un significado. Es lo que ocurre en:

como un cosaco -ca. adv. Mucho o en gran cantidad. Frec con el v beber. $\|$ (Seco, Andrés y Ramos, 2004, p. 328).

\section{Notas sobre la delimitación y clasificación de las comparativas fraseológicas}

Son divergentes las opiniones sobre la delimitación y la consiguiente clasificación de las unidades pluriverbales que contienen estructuras comparativas; en consecuencia, esta problemática se pone de manifiesto en los distintos diccionarios que las registran. Tanto en el nivel del análisis teórico como en la aplicación lexicográfica, es común encontrar distintas soluciones, a saber:

a) La unidad fraseológica es locución, verbal o adjetiva según sea el núcleo y la función sintáctica de la unidad pluriverbal.

b) La unidad fraseológica es colocación compleja de un verbo o un adjetivo y una locución adverbial.

c) La unidad fraseológica es locución adverbial, adjetiva o policategorial conformada únicamente por la expresión comparativa.

d) La unidad fraseológica es locución elativa. 


\subsection{Locuciones verbales o adjetivas}

\subsubsection{Locuciones verbales}

De acuerdo con la primera solución, las comparativas fraseológicas que estamos comentando se delimitan y se clasifican como locuciones verbales o adjetivas según sea el núcleo sintagmático y su funcionamiento sintáctico. Por ejemplo, categorizadas como locuciones verbales tenemos las siguientes unidades pluriverbales, de núcleo verbal, con estructura comparativa y sentido ponderativo:

dormir como un lirón

beber como un cosaco

llorar como una Magdalena

hablar como un loro.

pasar más hambre que un ratón de iglesia.

estar/ponerse (rojo) como un tomate

estar (loco) como una cabra

estar (sordo) como una tapia

Para advertir las divergencias en la delimitación y clasificación lexicográfica de este tipo de unidades pluriverbales, podemos observar el tratamiento que recibe la secuencia (dormir) como un lirón en una muestra de diccionarios, ${ }^{4}$ donde el Diccionario de la Lengua

4 Utilizamos las siguientes siglas para referirnos a los diccionarios consultados, las ordenamos alfabéticamente:

DAA: Diccionario de americanismos (Asociación de Academias de la Lengua Española, 2010).

DCA: Diccionario de costarriqueñismos (Agüero Chaves, 1996).

DCSM: Diccionario Clave (S. M., 2016). 
Española (DLE) la analiza y la clasifica como locución verbal, el Diccionario fraseológico documentado del español actual (DFDEA) la registra sin el verbo y sin asignarle propiamente una categoría y el Diccionario de uso del español (DUE) no llega a establecer una unidad fraseológica, sino que explica el uso del sustantivo lirón en el contexto sintáctico de una comparación:

DLE (DRAE)

lirón ${ }^{1}$

dormir como un lirón 1. loc. verb. coloq. Dormir mucho o de continuo.

\section{DFDEA}

\section{LIRÓN}

como un lirón. (col) Constr de sent comparativo usada para ponderar lo profundamente que duerme una pers. Gralm con el v dormir.

\section{DUE}

lirón ${ }^{1}$ (...) 2 Como nombre calificativo o como término de comparación se aplica a la persona que duerme mucho o que está profundamente dormida: 'Es un lirón. He dormido toda la noche como un lirón'.

En el siguiente ejemplo (estar como una cabra), en el que el núcleo verbal es un verbo gramaticalizado, tenemos que el DLE analiza y clasifica la unidad fraseológica estar como una cabra como locución verbal, mientras que el DFDEA la registra sin el verbo, como una cabra, y sin asignarle propiamente una categoría relativa a las clases de palabras (locución adjetiva o locución adverbial) y el Diccionario fraseológico del español moderno (DFEM) la recoge como locución verbal con los verbos estar y ponerse, estar/ponerse u.p. (como una) cabra, y con la forma comparativa como un elemento opcional:

DDLC: Diccionari descriptiu de la llengua catalana (Institut d'Estudis Catalans, 2014)

DFDEA: Diccionario fraseológico del español actual (Seco, Andrés y Ramos, 2004).

DFEM: Diccionario fraseológico del español moderno (Varela y Kubarth, 1996).

DFE: Diccionario de fraseología española (Cantera Ortiz de Urbina y Gomis Blanco, 2007).

DLAEE: Diccionario de locuciones adverbiales para la enseñanza del español (Penadés Martínez, 2005).

DLE: Diccionario de la lengua española (Real Academia Española, 2014).

DUE: Diccionario de uso del español (Moliner, 2008).

NDCQ: Nuevo diccionario de costarriqueñismos (Quesada Pacheco, 2007). 


\section{DLE:}

\section{cabra}

estar como una cabra 1. loc. verb. coloq. Estar loco, chiflado.

DFDEA:

\section{CABRA}

como una cabra. (col) Constr de sent comparativo usada para ponderar la locura. Frec con el adj loco.

\section{DFEM:}

\section{cabra}

estar/ponerse u.p. (como una) cabra Estar/ponerse loco: «Ríe y habla en solitario; el pobre hombre está cabra».

\subsubsection{Locuciones adjetivas}

Categorizadas como locuciones adjetivas, tenemos las que tienen un adjetivo como núcleo seguido de una estructura comparativa, por ejemplo:

negro como el carbón

rojo como un tomate

loco como una cabra

sordo como una tapia

Para ilustrar nuevamente las discrepancias de las que venimos hablando tenemos, por un lado, el Diccionario de fraseología española (DFE), que registra negro como el carbón como locución adjetiva, incluyendo el adjetivo negro como parte de la unidad fraseológica; mientras que, por otro lado, el DFDEA registra la unidad como el carbón, sin el adjetivo: 
DFE:

NEGRO

Negro como una endrina/ como el carbón/ como el ébano. Muy negro.

DFDEA:

CARBÓN

como el carbón. Constr de sent comparativo usada para ponderar la negrura. Frec con el adj negro.

\subsection{Colocaciones complejas V/Adj + Loc Adv}

De acuerdo con la segunda solución, las comparativas fraseológicas forman colocaciones complejas (Koike, 2001, pp. 55-60; García-Page, 2005), fenómeno fraseológico que se describe como la coocurrencia léxica de una unidad simple, que puede ser un verbo o un adjetivo, y una locución adverbial, donde dicha coaparición está condicionada por determinadas restricciones léxicas, es decir, uno de los elementos impone la presencia del otro. En estos casos, la locución adverbial, que tiene significado idiomático, muestra una preferencia léxica y selecciona un verbo o un adjetivo que mantiene su significado literal (Koike, 2001, p. 58).

Por ejemplo, en el grupo de las colocaciones con base verbal ( $\mathrm{V}+\mathrm{loc}$. adv.) se ubicarían las combinaciones:

dormir como un lirón

beber como un cosaco

llorar como una Magdalena

caer como una bomba

caer como un balde de agua fría 
Y en el grupo de las colocaciones con base adjetiva (Adj + loc. adv.) las combinaciones:

negro como el carbón

rojo como un tomate

loco como una cabra

sordo como una tapia

claro como el agua

limpio como un ajito

Las implicaciones lexicográficas de estos análisis se ponen de manifiesto en los artículos de los diccionarios que venimos comentando. Es lo que ocurre cuando en el interior del artículo lexicográfico se incluyen advertencias o indicaciones relativas a la combinatoria habitual o frecuente, del tipo: "Generalmente con el verbo dormir", "Frecuente con el adjetivo negro", "Frecuente con el adjetivo loco", etc.

\subsection{Locuciones conformadas únicamente por la expresión comparativa}

De acuerdo con la tercera solución, únicamente el segmento encabezado por el elemento como es la unidad locucional, los demás elementos vinculados a la comparativa pertenecen a la combinatoria libre o, si se prefiere, a la combinatoria semilibre propia de las colocaciones. A diferencia de aquel análisis de las colocaciones complejas de tipo V/Adj + Loc Adv, donde la unidad fraseológica -la colocación- abarca tanto el verbo/adjetivo como la estructura comparativa, en este caso la unidad fraseológica es únicamente la parte que expresa la comparación y, además, se amplían las posibilidades para clasificar la locución de acuerdo con la función que esta pudiera desempeñar en los distintos contextos sintácticos en que aparece. Se trata, pues, de locuciones adverbiales, locuciones adjetivas y locuciones policategoriales según sea el contexto sintáctico explícito. 
Desde este punto de vista, parece privar el análisis sincrónico sobre el diacrónico al entenderse que en la actualidad, en la sincronía de la obra lexicográfica, lo más frecuente es que no se exprese la noción comparada, por ejemplo, "la limpieza" en el costarriqueñismo fraseológico como un ajito, que registran el Nuevo diccionario de costarriqueñismos (NDCQ) de Miguel Ángel Quesada y el Diccionario de americanismos (DAA) de la Asociación de Academias de la Lengua Española:

NDCQ:

ajito m. como un ajito loc. adv. De aspecto muy limpio (Tener la casa como un ajito).

DAA:

ajito. ... a. \|| como un . loc. adv. CR. Muy limpio. rur.

Si de asignarles una categoría gramatical se trata, las construcciones comparativas así delimitadas, esto es, tomando únicamente el segmento encabezado por como, pueden llevar la etiqueta de locución adverbial, la etiqueta de locución adjetiva o ambas etiquetas (locución policategorial).

Por otro lado, subrayamos el hecho de que el contenido semántico del adjetivo elíptico o tácito -o si se prefiere: el adjetivo no analizado como formante de la locuciónpasa a formar parte del contenido referencial de la unidad fraseológica, lo cual suele verse reflejado en las definiciones lexicográficas, sea como parte de la definición propiamente dicha o como un contorno. ${ }^{5}$ En el Diccionari descriptiu de la llengua catalana (Institut d'Estudis Catalans, 2014) encontramos un estupendo ejemplo de esto último, donde el adjetivo loco (boig) aparece incorporado a la definición, en primer lugar, como un componente semántico de la definición propiamente dicha ("com una cabra loc. adj. 1. [...] completament boig") y, en segundo lugar, como un contorno de la definición (“com una cabra loc. $a d v$. 1. [...] completament [boig]"): ${ }^{6}$

5 Véase Seco (2003) y Ahumada (1987).

6 A continuación traducimos el artículo: "cabra f. (cabras). como una cabra loc. adj. 1. [N $\mathrm{N}_{1}$ (está) LOC] $\left(\mathrm{N}_{1} \text { [humano]) [Alguien] }\right]_{1}$ completamente loco. Cervantes ya nos había advertido que su hombre estaba como una cabra, y supongo que la psiquiatría actual tiene bien estudiada y catalogada la enfermedad que aquejaba

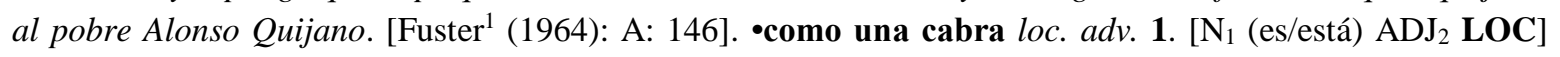


cabra f. (cabres)

com una cabra loc. adj. 1. [ $\mathrm{N}_{1}$ (està) LOC] ( $\mathrm{N}_{1}[\text { humà]) [Algú] }]_{1}$ completament boig. Cervantes ja ens havia advertit que el seu home estava com una cabra, $i$ suposo que la psiquiatria actual té ben estudiada i catalogada la malaltia que afligia el pobre Alonso Quijano. [Fuster ${ }^{1}$ (1964): A, p. 146].

-com una cabra loc. $a d v$. 1. [ $\mathrm{N}_{1}$ (és/està) $\mathrm{ADJ}_{2}$ LOC] ( $\mathrm{N}_{1}\left[\right.$ humà]; $\mathrm{ADJ}_{2}[$ boig]) [Algú] $]_{1}$ completament [boig]2. El que et passa és que ets boig com una cabra. [Bonet (1969): N, p. 139].

De acuerdo con esta perspectiva, podemos considerar los siguientes análisis:

\subsubsection{Locución adverbial [1]}

Cuando la locución incide sobre un verbo predicativo, ejerciendo algún tipo de modificación semántica sobre el proceso verbal, no suele haber mayores complicaciones en etiquetar la unidad fraseológica como locución adverbial: como un lirón (Dormía como un lirón), como un cosaco (Bebía como un cosaco), como una Magdalena (Lloraba como una Magdalena). Del español de Costa Rica, podemos citar como un cachiflín 'a toda velocidad' (Salió/ se levantó/ pasó / se fue/ saltó / bajó... como un cachiflín).

\subsubsection{Locución adverbial [2]}

La unidad fraseológica puede analizarse (o etiquetarse) como locución adverbial si en su contexto sintáctico aparece expreso el adjetivo, ya con sentido recto ya con traslaticio, que es base de la comparación y sobre el cual entendemos que la locución incide: como su madre lo trajo al mundo (Nunca la había visto desnuda como su madre la trajo al mundo), como una cabra (Estás loco como una cabra). Algunas locuciones registradas en los

$\left(\mathrm{N}_{1}\left[\text { humano]; } \mathrm{ADJ}_{2}[\mathrm{loco}]\right) \text { [Alguien }\right]_{1}$ completamente $\left[\mathrm{loco}_{2}\right.$. Lo que te pasa es que estás loco como una cabra. [Bonet (1969): N: 139]". 
diccionarios del español de Costa Rica son: como un ajito (La casa quedó limpia como un ajito), como chaqueta de salonero (Estoy limpio como chaqueta de salonero), como cuello de monja $^{7}$ (Ahorita estoy limpio como cuello de monja), como un caimito (Lo dejó morado como un caimito).

\subsubsection{Locución adjetiva}

Cuando estas unidades fraseológicas de estructura comparativa inciden de manera habitual directamente sobre sustantivos, no suele existir problema en etiquetarlas como locuciones adjetivas, por ejemplo, como una catedral (Una verdad como una catedral). Ahora bien, cuando unidades de este tipo funcionan como atributos en construcciones con el verbo estar y con otros verbos pseudocopulativos, como ocurre en "El mantenimiento de esta playa, que está como un ajito, ha sido un esfuerzo de todos los vecinos", "Lavé el carro y quedó como un ajito" y "El muchacho se puso como una cabra, pero el hermano lo tranquilizó"; o como complementos predicativos con verbos plenos, como en "Llegó como un ajito", pueden presentarse divergencias en su clasificación gramatical en los diccionarios.

Por ejemplo, dos obras académicas, el Diccionario de la lengua española y el Diccionario de americanismos, ofrecen clasificaciones distintas de dos locuciones equivalentes: como una patena aparece en el DLE como locución adjetiva y como un ajito aparece en el DAA como locución adverbial:

\section{DLE:}

\section{patena}

como una patena (...) 1. loc. adj. Muy limpio.

DAA:

ajito.

7 El adjetivo tieso también aparece ligado a esta secuencia, por ejemplo, en la forma más tieso que cuello de monja. El DCA, el NDCQ y el DAA no registran esta locución, sí la registra Shirley Arora en su estudio (1977, p. 153). El DCA y el NDCQ registran como supuesto costarriqueñismo el adjetivo tieso 'sin dinero'. 
a. \| como un . loc. adv. CR. Muy limpio. rur.

Por citar otro ejemplo, para la locución como una cabra también observamos análisis divergentes entre el Diccionario de locuciones adverbiales para la enseñanza del español (DLAEE) de Inmaculada Penadéz Martínez y el Diccionario Clave en línea (DCSM) de la Editorial SM. El primero la marca como locución adverbial mientras que el segundo como locución adjetiva. En los ejemplos de uno y otro diccionario la locución se combina con el verbo estar:

\section{DLAEE:}

como una cabra $a d v$. infor. En completo estado de locura: Estoy en la cocina bailando y entran mis sobrinas y me dicen: "Tía, tú estás como una cabra".

DCSM:

cabra.

como una cabra loc.adj. col. Muy loco: Para vestirse de forma tan extravagante hay que estar como una cabra.

\subsubsection{Locución policategorial (adjetiva y adverbial)}

Al igual que muchas unidades monoverbales, las locuciones con estructura comparativa pueden analizarse, ya se ha visto, como locuciones policategoriales, con lo cual, al momento de registrarlas en la obra lexicográfica llevarían una doble etiqueta gramatical o se incluiría una acepción por cada categoría. Por ejemplo, la doble marcación como locución adjetiva y locución adverbial para la locución del español de Costa Rica como un ajito sería consecuente con las siguientes ocurrencias que fácilmente recuperamos de internet. Como locución adjetiva: "El mantenimiento de esta playa, que está como un ajito, ha sido un esfuerzo en conjunto de la comunidad organizada, el gobierno local y el complejo Punta Leona" (canara.org); y como locución adverbial: "Sé que a ninguno de nosotros le dolerá pagar unos 300-500 para utilizar un servicio sanitario digno, con papel 
higiénico y no con olotes, con buen olor a cloro y limpio como un ajito" (playasdelcoco.ticoblogger.com).

Podemos ofrecer unas definiciones básicas, acompañadas de sus respectivas marcas y con los ejemplos de uso que las documentan:

como un ajito. I loc. adj. 1. completamente limpio. En todos los pueblos hay personas que mantienen las calles como un ajito y en Turrialba esto tiene un toque femenino (teletica.com). II loc. adv. 2. [limpio] por completo. Por la noche toditico queda bien ordenadito, porque, además de pizpireta, Azucena es limpia como un ajito y ordenada (nación.com).

\subsection{Locuciones elativas}

Por último, según la cuarta solución mencionada más arriba, las estructuras comparativas fijas a las que nos referimos serían analizadas como locuciones elativas. Alberto Zuluaga (1980, pp. 146-149) clasifica en un grupo aparte las locuciones que comportan un valor intensificador, entre ellas las construcciones comparativas fraseológicas. El hecho de que el Diccionario fraseológico documentado del español actual de Seco, Andrés y Ramos no agrupe muchas de estas unidades con las locuciones adverbiales o las locuciones adjetivas mediante las respectivas marcas gramaticales, sino

que las describa como "construcciones de sentido comparativo usadas para ponderar", induce a pensar que son entendidas, en lo que respecta a su posible clasificación y según el planteamiento de Zuluaga, como un tipo de "construcción" distinto de las locuciones nominales, adjetivas, verbales y adverbiales. De hecho, este autor las subdivide en locuciones que "elativizan verbos", "elativizan sustantivos" y "elativizan adjetivos". 


\section{Conclusiones}

A partir de la evidencia encontrada en la práctica lexicográfica y con base en algunas nociones teóricas de los estudios fraseológicos, hemos presentado sistemáticamente las distintas soluciones aplicadas por varios diccionarios para registrar las construcciones comparativas fraseológicas cuya estructura básica es (V/Adj) + como + SN. Sin embargo, está claro, el universo de las comparativas fraseológicas es mucho más complejo que lo presentado aquí, y los criterios para determinar cómo habrán de registrarse en los diccionarios no son menos complejos.

Se ha mostrado que los diccionarios estudiados difieren en la manera de segmentar las locuciones con estructura comparativa: hay divergencias en el establecimiento de sus lindes. Esto repercute en distintos aspectos del tratamiento lexicográfico de dichas unidades, tales como la marcación gramatical, la definición, la ejemplificación y la misma estructura interna de los artículos.

Las unidades pluriverbales, al igual que las unidades simples, son susceptibles de llevar una etiqueta que muestre su adscripción a una clase gramatical, por lo tanto, no parece justificable que en un determinado diccionario las palabras (las unidades simples) lleven sus respectivas marcas gramaticales y las locuciones no vayan acompañadas de tan importante información.

La asignación de la etiqueta gramatical depende del análisis que se practique sobre la unidad en cuestión en cuanto a sus características morfológicas y su funcionamiento en los distintos contextos sintácticos; en el caso de las locuciones, la determinación de sus lindes suele constituir un factor más del cual depende la categoría a la que se adscriban, y, por consiguiente, la marca gramatical que se les asigne. Así, encontramos construcciones comparativas que forman parte de secuencias registradas, etiquetadas y definidas unas veces como locuciones verbales y otras como locuciones de distinta categoría gramatical. Los verbos que intervienen en estas combinaciones pueden ser copulativos, pseudocopulativos o plenos: andar/estar como gata de parto, caer como (un) balde de agua fría, estar como agua para chocolate, estar como chaqueta de salonero, estar como un 
ajito, estar/ser como un alambre, correr como (un) cachiflín, resultar/salir/ser más caro el caldo que los huevos, salir como semilla de guaba, ser más hojas que tamales.

Así pues, la delimitación sintagmática de estas unidades suele presentar discrepancias, tanto de una obra a otra como dentro de un mismo diccionario; por ejemplo, la secuencia estar como agua para chocolate es descrita como locución verbal en el DCA y en el NDCQ, mientras que como agua para chocolate lleva las marcas locución adjetiva y locución adverbial en el DAA:

DCA:

agua. f. (...)// Estar como agua para chocolate. Loc. fig. fam. Estar muy enfadado, furioso. //

NDCQ:

agua $\mathrm{f} .(\ldots ..) / /$ estar como agua para chocolate loc. Estar furioso.//

DAA:

agua.

\| como para chocolate.

i. loc. adj. $M x, G u, E S, P R$. Referido a persona, muy enojada, furiosa, a punto de estallar en cólera. pop + cult $\rightarrow$ espon.

ii. loc. adv. $M x, C R$. Con mucha cólera.

La definición y el ejemplo de uso se ven igualmente afectados por las fluctuaciones en el análisis de estas unidades. La definición debe ser semántica y funcionalmente equivalente a la unidad definida, de manera que, si dicha unidad se analiza como locución verbal, su definición necesariamente deberá arrancar con un verbo, mientras que, si la unidad se analiza como locución adjetiva o adverbial, su definición deberá formularse según los criterios lexicográficos establecidos para los adjetivos y los adverbios. ${ }^{8}$

Por su parte, el ejemplo de uso debe contextualizar y documentar la forma que aparece como lema, no una forma alternativa o variante. En este sentido, ante una secuencia como estar como agua para chocolate analizada como locución verbal convendría tener en 
cuenta que estar no es el único verbo gramaticalizado que puede aparecer en esa posición, y que enunciados como "La reina cayó con un ataque y el rey se puso como agua para chocolate"9 o "Farinha quedó como agua para chocolate con el presidente manudo y toda su directiva" ${ }^{10}$ no pueden aparecer como ejemplos para estar como agua para chocolate.

En definitiva, cuestiones como las expuestas tienen implicaciones en la uniformidad de los repertorios lexicográficos.

\section{Bibliografía}

Agüero Chaves, Arturo. (1996). Diccionario de costarriqueñismos. San José, C. R.: Asamblea Legislativa.

Ahumada Lara, Ignacio. (1987). Contorno de la definición verbal y régimen lexemático: su indicación en la lexicografía hispánica. En Amistad a lo largo. Estudios en memoria de J. Fernández Sevilla y N. Marín (pp. 13-25). Granada: Universidad de Granada.

Arora, Shirley L. (1977). Proverbial comparisons and related expressions in Spanish. Recorded in Los Angeles, California. California: University of California Press.

Asociación de Academias de la Lengua Española. (2010). Diccionario de americanismos. Madrid: Santillana Ediciones Generales.

Cantera Ortiz de Urbina, Jesús y Pedro Gomis Blanco. (2007). Diccionario de fraseología española: locuciones, idiotismos, modismos y frases hechas usuales en español. Madrid: Abada Editores.

Rey-Debove, Josette. (1971). Étude linguistique et sémiotique des dictionnaires français contemporains. Berlin, Boston: De Gruyter Mouton.

Lyra, Carmen. (2012). Cuentos de mi tía Panchita [recurso electrónico]. San José: Imprenta Nacional.

9 Tomado de Carmen Lyra (2012) Cuentos de mi tía Panchita [recurso electrónico]. San José: Imprenta Nacional.

10 Tomado de La Teja del 7 de abril de 2017 a través de https://www.pressreader.com/costa-rica/la-teja 
García-Page, Mario. (2005). Colocaciones simples y complejas: diferencias estructurales. En R. Almela Pérez, E. Ramón Trives y G. Wotjak (Eds.), Fraseología contrastiva: con ejemplos tomados del alemán, español, francés e italiano (pp. 145-167). Murcia: Universidad de Murcia.

García-Page, Mario. (2008a). Introducción a la fraseología española. Barcelona, España: Anthropos Editorial.

García-Page, Mario. (2008b). La comparativa de intensidad: la función del estereotipo. Verba: Anuario galego de filoloxia, (35), 143-178.

García-Page, Mario. (2013). Colocaciones léxicas con locuciones adverbiales integradas. En A. Pamies Bertrán (Ed.), De lingüística, traducción y léxico-fraseología. Homenaje a Juan de Dios Luque Durán (pp. 472-488). Granada: Comares.

Gutiérrez Ordóñez, Salvador. (1997). Estructuras comparativas. Madrid: Arco/Libros.

Institut d'Estudis Catalans. (mayo de 2014). Diccionari descritiu de la llengua catalana. Recuperado de http://dcc.iec.cat/ddlc/index.asp

Koike, Kazumi. (2001). Colocaciones léxicas en el español actual: estudio formal y léxicosemántico. Alcalá de Henares: Universidad de Alcalá/Universidad de Takushoku.

Mellado Blanco, Carmen. (2012). Las comparaciones fijas en alemán y español: algunos apuntes contrastivos en torno a la imagen. Linred: Lingüística en la Red, (10), 1-32.

Moliner, María. (2008). Diccionario de uso del español. Edición electrónica. Madrid: Gredos.

Olímpio de Oliveira Silva, María Eugenia. (2007). Fraseografía teórica y práctica. Frankfurt: Peter Lang. Internationaler Verlag der Wissenschaften.

Penadés Martínez, Inmaculada. (2005). Diccionario de locuciones adverbiales para la enseñanza del español. Madrid: Arco Libros.

Penadés Martínez, Inmaculada. (2010). Las construcciones comparativas en los diccionarios fraseológicos. En M. A. Castillo Carballo y J. M. García Platero (Eds.), La lexicografía en su dimensión teórica (pp. 473-493). Málaga: Servicio de Publicaciones de la Universidad de Málaga. 
Porto Dapena, José Álvaro. (2002). Manual de técnica lexicográfica. Madrid, Esp.: Arco/Libros.

Quesada Pacheco, Miguel Ángel. (2007). Nuevo diccionario de costarriqueñismos (4 ed.). Cartago C.R.: Editorial Tecnológica de Costa Rica.

Real Academia Española. (2014). Diccionario de la lengua española (vigésimotercera ed.). Madrid: Espasa.

Real Academia Española; Asociación de Academias de la Lengua Española. (2010). Nueva gramática de la lengua española. Manual. Madrid: Espasa Libros.

S. M. (8 de agosto de 2016). Diccionario Clave. Diccionario de uso del español actual. Recuperado de http://clave.smdiccionarios.com/app.php

Seco, Manuel. (2003). Estudios de lexicografía española (segunda ed.). Madrid: Gredos.

Seco, Manuel, Andrés, Olimpia y Ramos, Gabino. (2004). Diccionario fraseológico documentado del español actual: Locuciones y modismos españoles. Madrid: Aguilar.

Suñer Gratacós, Avelina. (2013). Las comparativas prototípicas. En L. Sáez y C. Sánchez López (Eds.), Las construcciones comparativas (pp. 337-369). Madrid: Visor Libros.

Varela, Fernando y Kubarth, Hugo. (1996). Diccionario fraseológico del español moderno. Madrid: Gredos.

Zuluaga, Alberto. (1980). Introducción al estudio de las expresiones fijas. Frankfurt/Berna: Verlag Peter D. Lang.

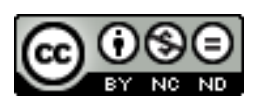

Esta obra está bajo una licencia de Creative Commons Reconocimiento-NoComercial$\underline{\text { SinObraDerivada 4.0 Internacional }}$ 